Article

\title{
Design and Manufacturing of an Innovative Triple-Layer Thermo-Insulated Fabric
}

\author{
Rocco Furferi ${ }^{1, *(\mathbb{D}}$, Franco Mantellassi ${ }^{2}$ and Yary Volpe ${ }^{1}$ (D) \\ 1 Department of Industrial Technology, University of Florence, 50139 Firenze, Italy; yary.volpe@unifi.it \\ 2 Manteco Company, 59013 Prato, Italy; franco@manteco.com \\ * Correspondence: rocco.furferi@unifi.it; Tel.: +39-055-2758741
}

Received: 6 December 2019; Accepted: 13 January 2020; Published: 18 January 2020

\begin{abstract}
Materials used for creating fabrics featuring insulation and thermoregulation are typically made of multi-layer materials consisting of two outer layers and inner padding, traditionally made from goose or duck feathers or even with synthetic materials. In this context, the development of a fabric in which the insulation is carried out directly thanks to the structure of its weave, i.e., where the thermoregulation function is entrusted to one of the yarns (suitably volumized to reduce its density and trap the air) may be an important improvement compared to the state of the art. Accordingly, the present work describes the development of a new kind of triple-layer thermo-insulated innovative fabric (named T4Innovation), in which the thermal insulation is not obtained by means of a padding but rather through the use of appropriate volumized yarns, able to ensure thermal insulation in a reduced thickness. This fabric is manufactured in a single weaving phase, greatly facilitating the subsequent operations of the garment maker. The designed and manufactured fabric was extensively tested to assess its performance. The test demonstrated the effectiveness of such a new class of textile product in terms of thermal performance, which is comparable to the ones of a padded material. Since T4Innovation demonstrates aesthetic properties very close to that of traditional unpadded fabrics, its future commercialization could open new horizons in terms of design, fashion, and style, which are cornerstones of the fashion textile industry.
\end{abstract}

Keywords: textile design; thermoregulation; triple-layer weaving

\section{Introduction}

The materials used for insulation and thermoregulation are typically made of multi-layer materials consisting of two outer layers and an inner padding traditionally made from goose or duck feathers [1]. These are light and compressible products in which thermal insulation is obtained by exploiting the feather's ability to trap the air, which is widely known as one of the best thermal insulators [2].

Unfortunately, in the presence of moisture, the thermal insulation for such products is drastically reduced - if the padding is exposed to water and the surface fabric is not properly isolated, the thermal insulation drops to zero [3]. Moreover, multilayer materials filled with feathers are expensive and, often, the origin of natural material often involves the presence of impurities or substances dangerous to health. The scientific and technological attention of the Textile sector has therefore shifted towards multi-layer products filled with synthetic materials (i.e., thermal padding). In particular, a sufficient mix of textile fibers and air is achieved to guarantee the desired thermal insulation by using a series of superimposed layers of soft, very low-density carded fibers [4].

This technology makes it possible to produce products such as, for instance, down jackets that are generally less expensive than the ones made of goose plumes-at the same time, multi-layered products padded with fibers may be rendered hypoallergenic, washable, and water-resistant. However, the injected materials are subject to poor stability even after a short time of use or after a few washes 
because they tend to form lumps, "voids", or leakage of the fibers from the layers of support with a significant reduction in the thermal characteristics of the finished product [5]. Furthermore, for these products there subsists a linear correlation between the thickness of the insulating layer and the thermal insulation characteristics of the finished product, which results in high thicknesses. The thickness reduction of padded fabrics (preserving their thermal insulation capacity) is still a subject of study both in scientific literature [6-9] and in the market, as also demonstrated by a large and growing number of brands and products for padding obtained by appropriately mixing synthetic fibers. Not by chance, considerable progress was made in recent years in several commercial products on the structure of the internal padding. PrimaLoft ${ }^{\circledR}$, designed for the US Army, was the first product in which microfibers were used to optimize the ratio between heat and weight of the insulation material.

From this forerunner, there are now numerous products in which the thermal wadding is obtained with synthetic materials optimized in terms of weight and size by testing numerous combinations of fibers: Polarguard ${ }^{\circledR}$, Heatseeker $^{\mathrm{TM}}$, Thinsulate ${ }^{\circledR}$, Lite Loft ${ }^{\mathrm{TM}}$, Thermolite ${ }^{\circledR}$, Thermoloft ${ }^{\circledR}$, Coreloft ${ }^{\mathrm{TM}}$, ThermaTek ${ }^{\mathrm{TM}}$, and Thermogreen ${ }^{\circledR}$ [10]. To date, the best commercial product able to guarantee thermoregulation using thermal wadding is Thermore ${ }^{\circledR}$ for which a particular production process has been developed, called SR, which allows reducing the thickness of the padding without significantly altering the thermal performance since the process reduces the thickness but not the amount of air trapped in the structure.

However, all state of the art products encompass a three-layer structure comprising two outer fabrics (with variable characteristics such as impermeability/permeability, resistance to friction, etc.) and a padding/system used for insulation (see Figure 1).

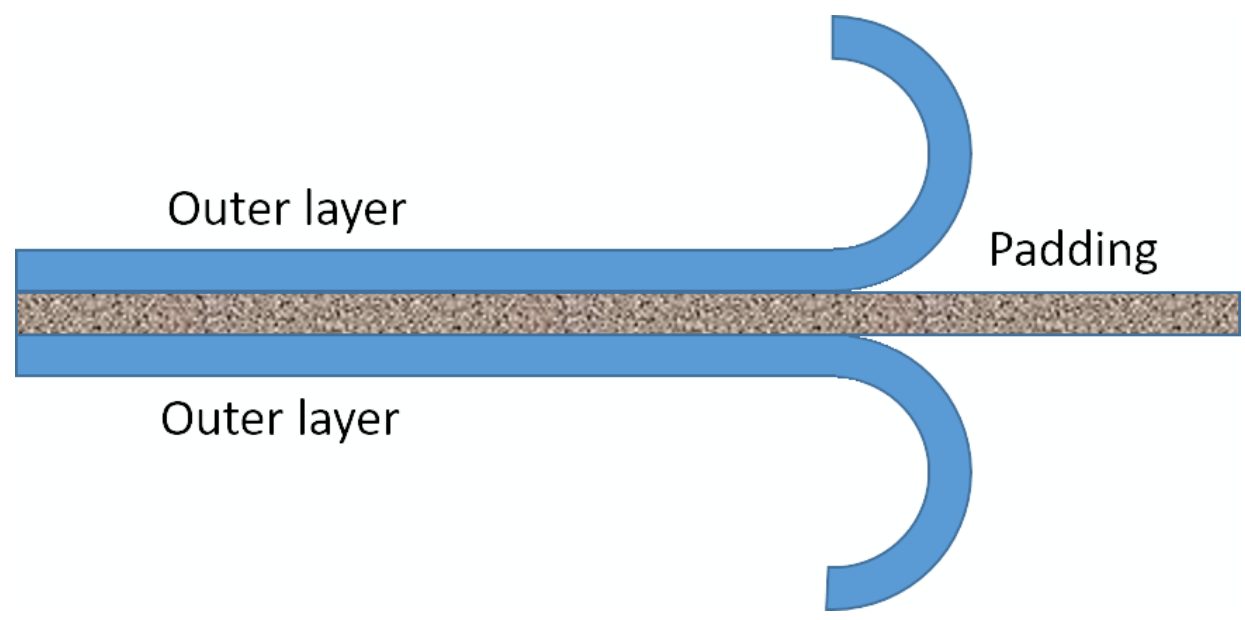

Figure 1. Typical structure of a three-layer fabric comprising two outer fabrics and an insulating padding.

A possible alternative to the traditional three-layer product, which could also partially fulfill the function of thermoregulation, is the non-woven fabric; although its water-repellent properties and, if made at low density, its thermal insulation characteristics, this type of fabric has never been used for designing fashion fabrics, mainly due to its unsophisticated appearance [11].

In this context, the development of a fabric in which the insulation is carried out directly thanks to the structure of its weave, i.e., where the thermoregulation function is entrusted to one of the yarns (suitably volumized to reduce its density and trap the air) may be an important improvement compared to the state of the art.

Accordingly, the main aim of the present work is to develop a new kind of triple-layer thermo-insulated innovative fabric (named T4Innovation), in which the thermal insulation is not obtained by means of a padding (natural or synthetic) but rather through the use of appropriate volumized yarns, able to ensure thermal insulation in a reduced thickness. This fabric can be manufactured in a single weaving process on the loom, greatly facilitating the subsequent operations 
of the garment maker. The creation of a fabric whose thermal performance is comparable to the ones of a padded material but with better aesthetic properties could open new horizons in terms of design, fashion, and style, which are cornerstones of the fashion textile industry.

In fact, the fabrics created using this unique method overcomes the drawbacks of the state of the art since it renders it possible to ensure thermal properties using a fabric where the "padding" is included within the fabric itself. The new fabric was conceived in the laboratories of Manteco s.p.a. Company, located in Prato, Italy.

\section{Materials and Methods}

With the aim of creating a new class of triple-layer thermo-insulated innovative fabrics, a number of tasks are carried out:

- Task 1: Definition of technical requirements for the innovative fabric.

- Task 2: Design of fibers and yarns composing the fabric.

- Task 3: Design of the weaves and manufacturing of fabric prototypes.

\subsection{Technical Requirements}

With the aim of designing the T4Innovation fabric, it is necessary to state a number of technical requirements based on the typical performance of winter fabrics required to act as thermoregulatory clothing. Such requirements are specified for both fibers and yarns composing the fabric, and for the fabric itself. Referring to fibers, there are no particular restrictions in terms of mechanical or thermal performance. Rather, it is strictly required to guarantee the absolute absence of heavy metals and of tetrachlorophenol (see Table 1) according to Oeko-Tex Standard.

Table 1. Technical requirements for fibers.

\begin{tabular}{ccc}
\hline Parameter & Standard & Requirements \\
\hline $\begin{array}{c}\text { Heavy metals (antimony, arsenic, lead, } \\
\text { cadmium, chromium, cobalt, nickel, } \\
\text { mercury, copper) }\end{array}$ & $\begin{array}{c}\text { http://www.oecotextiles.com/PDF/ } \\
\text { textile_industry_hazards.pdf }\end{array}$ & Absent $^{1}$ \\
\hline Tetrachlorophenol & $\begin{array}{c}\text { http://www.oecotextiles.com/PDF/ } \\
\text { textile_industry_hazards.pdf }\end{array}$ & Absent $^{2}$ \\
\hline $\begin{array}{l}{ }^{1} \text { Limited quantities are allowed by the current standard; maximum permitted limit is } 0.5 \mathrm{mg} / \mathrm{kg} .{ }^{2} \text { Maximum } \\
\text { allowed limit by normative is } 0.5 \mathrm{mg} / \mathrm{kg} .\end{array}$
\end{tabular}

The technical requirements for yarns are in Table 2. The most important parameters to be controlled are the volume and composition of the yarn. In fact, it is desirable to create a fabric with a consistent amount of wool with high density.

Table 2. Technical requirements for yarns.

\begin{tabular}{|c|c|c|}
\hline Parameter & Standard/Reference & Requirements \\
\hline Volume & [12] & $\begin{array}{c}+8 \% \text { with respect to conventional } \\
\text { wool yarns }\end{array}$ \\
\hline $\begin{array}{c}\text { Minimum amount of Wool (\%) for } \\
\text { volumized yarn }\end{array}$ & [13] & $75 \%$ \\
\hline
\end{tabular}

The most important requirements are, therefore, on the manufactured fabric-once verified that the fibers and yarns comply completely with the above-mentioned technical specifications, fabrics must meet the following technical requirements: 
- Lightness: garments made with the new fabric must weigh little in order to be carried in the backpack or worn. The aim is to create a fabric weighing between 200 and $450 \mathrm{~g} / \mathrm{m}^{2}$ and/or 500-600 denier.

- Water-vapor resistance: measured using the ISO-11092, also known as the Ret test [14]. In this test, the fabric is placed above a porous (sintered) metal plate which is heated [15]. Water is channeled into the metal plate, simulating perspiration. The plate is kept at a constant temperature. As water vapor passes through the plate and the fabric, it causes Evaporative Heat Loss and therefore more energy is needed to keep the plate at a constant temperature. Consequently, $\left.\operatorname{Ret}\left[\mathrm{m}^{2} \mathrm{~Pa}\right) / \mathrm{W}\right]$ is the measurement of the resistance to evaporative heat loss. The lower the RET value, the less resistance to moisture transfer and therefore higher breathability. Generally, softshell garments have Ret values from 8 to 13, while Gore-tex or Gore-tex-pro have Ret values from 4 to 6 . The objective of the new fabric is a Ret from 4 to 8 .

- Waterproofing: water-repellent garments have the characteristic of being waterproof to a modest level of rain. Water repellency is evaluated according to UNI EN 24,920. The water repellency value is given with an ISO index from 1 (lowest) to 5 (best). The objective for the new fabric is an ISO 3, 4 index.

- UV protection: is the ability of some fabrics to protect the skin from the action of ultraviolet rays. It is measured by the UPF (Ultraviolet Protection Factor) $\left[\mathrm{mJ} / \mathrm{cm}^{2}\right]$ for which it is possible to identify good protection with values from 15 to 24 and excellent protection when UPF is greater than 40. Despite the use of the innovative fabric is planned for winter garments, a supplementary requirement for the innovative fabric is its UV protection. This parameter should be controlled especially when the fabric is used for clothes to be used in mountains, where sun exposure can be very significant. The objective for the new fabric is a UPF between 25 and 40 .

- Clothing insulation. Measured in Clo $\left[\mathrm{K} \cdot \mathrm{m}^{2} \cdot \mathrm{W}^{-1}\right]$ such a parameter typically varies in the range [0-4] where zero value is related to the insulation on a naked subject placed in an environment with $21^{\circ} \mathrm{C}$ and $0.1 \mathrm{~m} / \mathrm{s}$ air movement and 4 is for heavy polar equipment. The objective of the new fabric is a clothing insulation value between 1 and 2.5 Clo.

- Pilling resistance: pilling is an undesired defect of textile fabrics, consisting of a surface characterized by a number of roughly spherical masses made of entangled fibers. Mainly caused by the abrasion of fabric surface occurring during the washing and wearing of fabrics, this defect needs to be accurately controlled and measured by companies working in the textile industry [16].

\subsection{Fibers and Yarns}

A volumized yarn is the starting point for the design of the new class of fabrics called T4Innovation. The raw materials selected for this purpose are two: (1) mercerized wool (WV), treated in tops with polyamide (PA) fractions (usually 80-20 percent percentage points) and (2) 100\% pure synthetic PA. Both raw materials were tested to verify their compliance with the strict requisites defined in Table 1 .

A fiber fineness (or transverse length) measurement was performed using a projection microscope (lanameter) for both the WV-PA mix and 100 percent nylon. The microscope used has a fixed magnification of $500 \times$, so that each interval in the screen corresponds to $0.002 \mathrm{~mm}$. In measurements on ribbons or wicks of parallel fibers, sampling is carried out by cutting off the external parts and pushing the remaining pieces onto the slide using $0.4-0.8 \mathrm{~mm}$ punches. This allows preventing the fibers from being arranged with the major axis of their cross section in the slide plane, thus distorting the measurement (longer sections due to the natural curl of the fibers, which is greater for the finer ones, are arranged more randomly). In the case of staple material, the specimen is formed by cutting the fibers with scissors in lengths between 0.5 and $1 \mathrm{~mm}$.

Selected wool fibers resulted in fineness averagely equal to $26 \mu \mathrm{m}$ with a Coefficient of Variation ${ }^{1}$ (The CV is the standard deviation SD divided by the mean fiber diameter $\times 100$. CV measures the fiber diameter variability as a percentage. CV tends to fall in the range of $15 \%$ to $30 \%$, with $15 \%$ 
being uniform wool, whilst $30 \%$ is highly variable wool.) CV equal to $25.4 \%$. Nylon fibers have an average diameter of $18 \mu \mathrm{m}$. Since such values fall in the range of workability of fibers, authors consider such selected raw materials the elective starting point for creating the yarns to be used for weaving the innovative fabric. Moreover, the measured CV for wool can be considered a typical value for volumized fibers.

After a number of attempts, it was decided to use, for the weft yarns, the wool-nylon mix while warp yarns are instead entirely composed by Synthetic Polyamide (nylon).

As far as the wool-nylon mix is concerned, it was necessary to act on the production process of the yarn. In particular, since the carded spinning is carried out with fibers of $40-50 \mathrm{~mm}$ while the new fibers to be processed are much longer (i.e., $>70 \mathrm{~mm}$ ), it was necessary to modify both the unraveling operations of the mixed fiber and of the cylinders in the ring-spinning machine. To this aim, the wool-based yarn is obtained by using a modified ring-spinning machine [17].

Such a system (shown in Figure 2) consists of a double roving unit capable of supplying both the core fibers (nylon) and the natural fibers wounded on such a core. Thanks to this double feeding mechanism, the volumized yarns are created without further processing, since one of the roving fibers (i.e., the left one in Figure 2), continuously fed, provides the synthetic fibers, while the other provides the wool fibers.

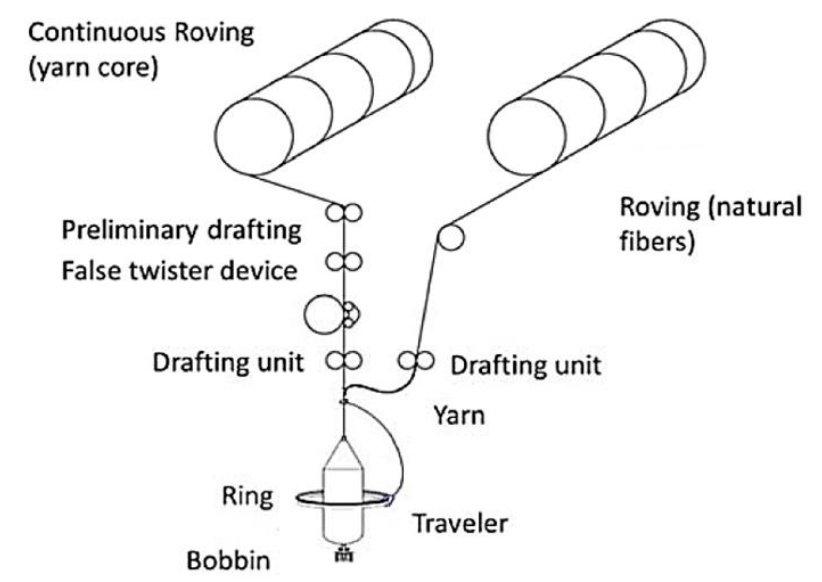

Figure 2. Scheme of the new ring spinning system provided with double drafting unit.

Since two spinning-fed rovings are used, no twisting is required to add nylon as the core of the yarn. This is added directly during the spinning phase. The subsequent twisting, which still occurs with double twist S-Z, allows a percentage of $4 \%$ of 50 DEN yarn to be added to the yarn core. The final composition of the yarn is given by about $67 \%$ wool and $33 \%$ nylon. In addition, at the end of the double stretch phase, the yarn is characterized by open fibers conferring a suitable volume; therefore, after spinning, the yarn does not require a vaporization phase.

Figure 3 shows a comparison between a typical yarn obtained by conventional ring spinning and the volumized one obtained with the new ring spinning system of Figure 4. It should be mentioned that both yarns are not handled with a cycle of steaming. 


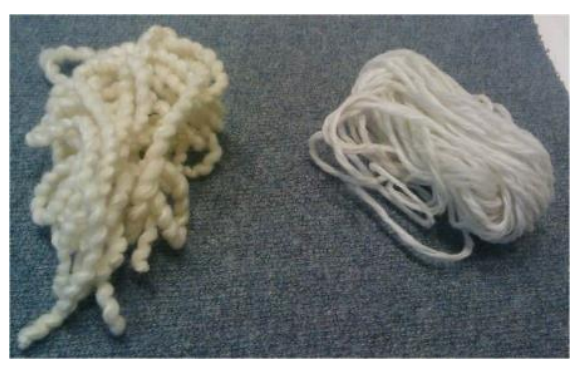

Figure 3. Double feeding system used to produce the volumized yarn. Comparison between a typical yarn obtained by adopting conventional ring-spinning and the volumized one.
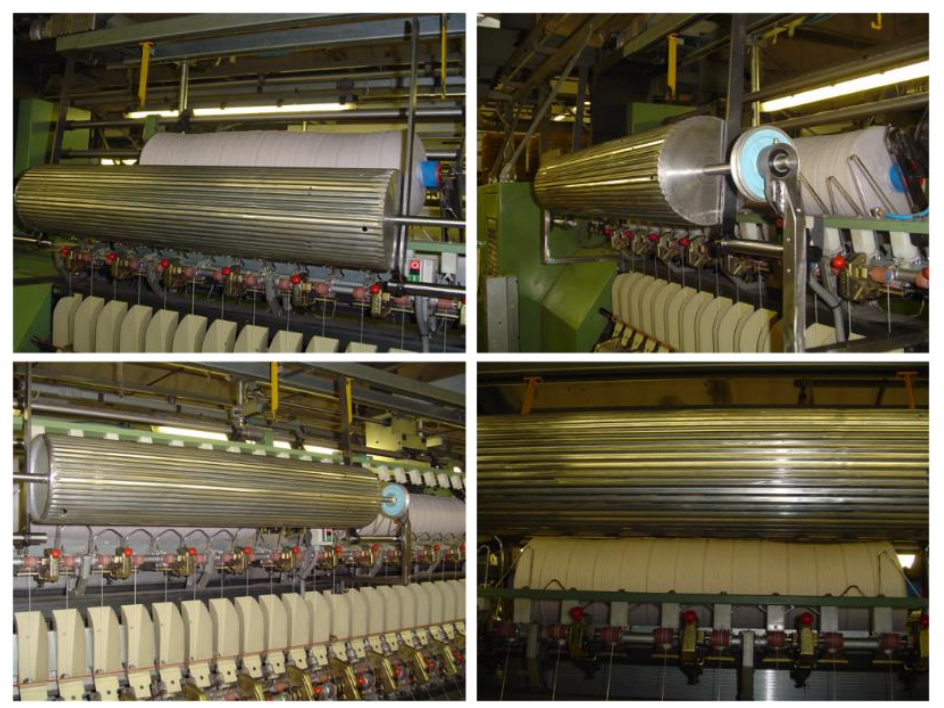

Figure 4. Double feeding system used to produce the volumized yarn.

With reference to the nylon yarns, it was necessary to carry out a texturing process; as known [18], this process exploits the physical and thermoplastic properties of synthetic yarns. Through the combination of the stretching action of the mechanical shafts with the friction of the spindle disks, the result is a voluminous, curled yarn with an elastic and covering strength. The texturing process was carried out using the false-torsion method, i.e., by twisting the wires and, at the same time, passing them through an electrically heated furnace at a temperature varying in the range $120-250{ }^{\circ} \mathrm{C}$. At the exit of the furnace, the yarns undergo an opposite twist. In order to fix the second twist and eliminate the elasticity, the yarns (collected in cylindrical bobbins) are placed in an autoclave and vaporized. For the development of the prototypes, texturing was applied to 8 Nylon garments ${ }^{2}$ (tex is a unit of measurement for linear density and corresponds to one gram per kilometer of yarn: It is used in the textile field for the titration of textile fibers. More commonly, decitex, abbreviated as dtex, is used, which corresponds to $1 \mathrm{~g}$ per $10 \mathrm{~km}$.) (78 dtex) each one composed by 23 filaments, for a final result of approximately $624 \mathrm{dtex}$. This process allows an increase in its volume and an increase of yarn elasticity after contact with heat and humidity. The choice of this type of product and process is ideal for use with wool yarns also due to its dyeing affinity.

\subsection{Fibers and Yarns Design and Manufacturing of the New Kind of Triple-Layer Thermo-Insulated Fabric}

Once the warp and weft yarns are realized, it is possible to design a new concept of triple-layer thermo-insulated fabric. The textile product, as depicted in Figure 4, consists of three layers comprising:

- A first woven protective layer (outer layer), designed to be the outer layer of the garment. Such a layer is treated with a non-formaldehyde crosslinking agent to convey waterproof properties. 
- An intermediate layer, which overlays the first protective ones. In such a layer, the volumized yarn is woven with a triple weave architecture. Such a middle layer is created by a single weaving operation, allowing the volumized yarns to be weaved once with the backrest.

- A second outer layer (inner layer), which is also of woven type.

The three layers are inseparably joined together by weaving (see Figure 5). The main innovation of the proposed fabric is to use a fabric obtained by weaving the volumized yarns along with the supporting yarn in nylon as an intermediate layer. In detail, to confer the desired volume of the layer thus granting the desired air entrapment for assuring the thermal insulation, the intermediate layer has a triple weave architecture. Furthermore, the fabric is obtained in one process on the loom, thus avoiding the need of joining together the internal and external layers in a second process phase.

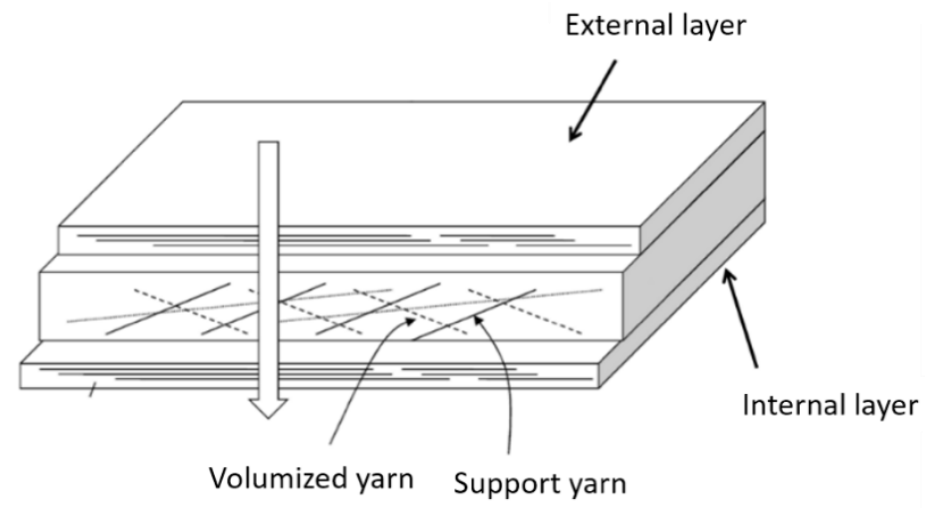

Figure 5. Structure of the devised triple-layer thermo-insulated fabric.

As is widely known [19], the weave of a fabric is graphically represented on checkered paper (technical paper) where the rows of vertical checkers represent the threads of the warp, and the rows of horizontal checkers represent the wefts. The full square indicates the point of intersection where the thread passes over the weft, while the empty square indicates that the thread passes under the weft.

Starting from the yarns defined in Section 2, two main fabric compositions for T4Innovation prototypes are set:

- $\quad$ Type 1: $60 \% \mathrm{WV}-40 \%$ PA

- $\quad$ Type 2: $67 \% \mathrm{WV}-33 \% \mathrm{PA}$

According to the different composition, and in order to test different possible solutions from both the technical and the aesthetic point of view, seven different prototypes were weaved, as shown in Table 3.

Table 3. T4Innovation prototypes and typologies.

\begin{tabular}{ccc}
\hline T4Innovation Prototype (Reference Code) & Typology & Color \\
\hline 284,291 & 1 & White \\
284,292 & 1 & Beige \\
284,293 & 1 & Blue \\
286,269 & 2 & Brown \\
285,980 & 2 & Black \\
285,989 & 2 & Red \\
286,290 & 1 & Green \\
\hline
\end{tabular}

For each of them, a textile CAD design of the triple weave to be used was carried out. Accordingly, each prototype is characterized by a different weave architecture and color. Figure 6 shows the architecture of the prototype labeled with code 285,989 . 


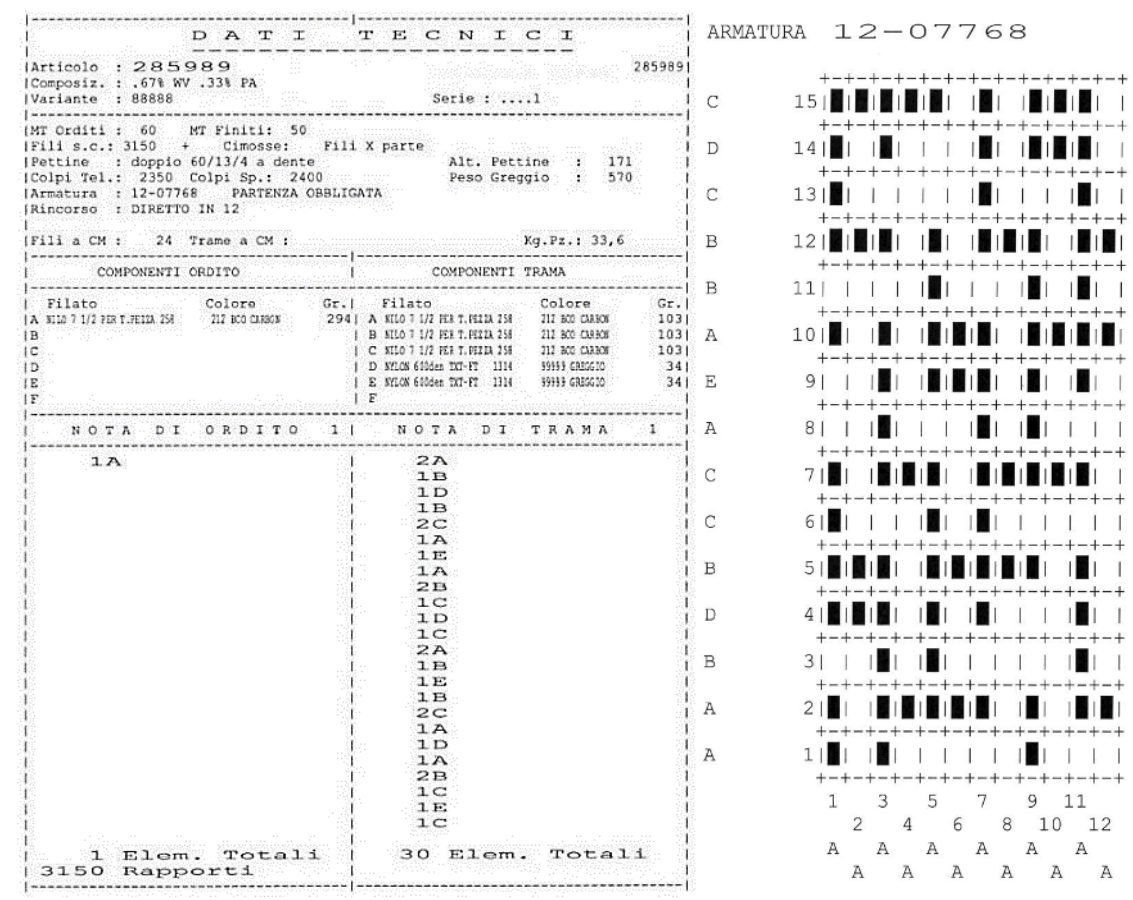

Figure 6. Triple weave design of the intermediate layer composing the new thermo-insulated fabric.

In order to confer the final quality characteristics, the raw fabric from the loom was finally subjected to the following appropriate finishing operations:

- Cleaning, i.e., the removal of impurities from the semi-finished product.

- Trimming, wetting-back, steaming and reeling; these operations confer the finished product a specific appearance or a particular hand to meet specific requirements of use or fashion. Moreover, they increase the resistance of the finished product to external physical, chemical or biological agents.

Figure 7 shows two of the seven prototypes of T4Innovation fabric obtained with, respectively, red-colored and beige-colored yarns.

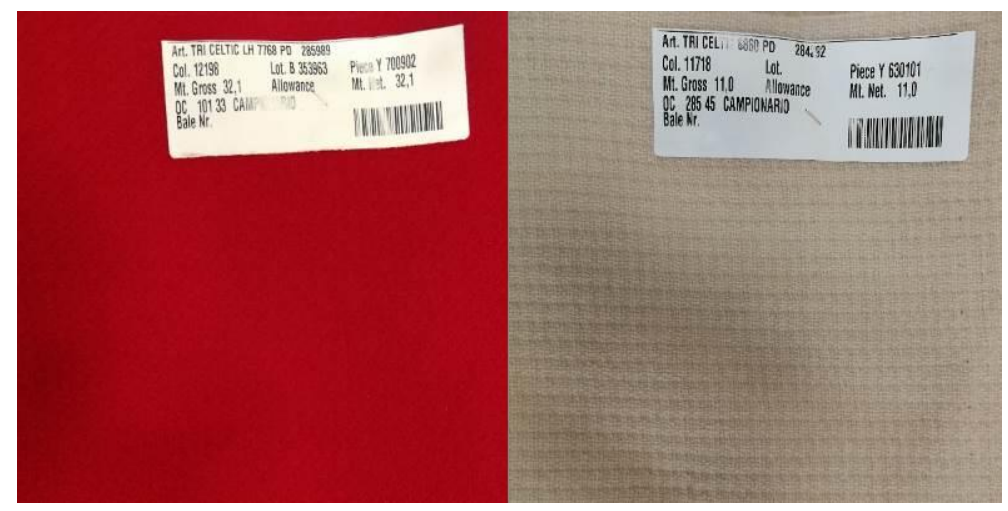

Figure 7. Two of the seven prototypes of T4Innovation.

\section{Results}

Once the various T4Innovation prototypes are available, it is possible to verify the actual compliance of the product with the technical requirements, set out in Section 1, through experimental tests. The first requirements to be verified are related to the yarns because, in the preliminary phase of the yarn design, compliance with the requirements described in Table 1 was yet met. In particular, 
volumized yarns were tested according to the standard mentioned in Table 2. The results obtained are in Table 4.

Table 4. Test results on volumized yarns.

\begin{tabular}{ccc}
\hline Parameter & Standard/Method Adopted & Obtained Results \\
\hline Volume & {$[12]$} & $+10 \%$ with respect to conventional \\
wool yarns \\
Minimum amount of Wool (\%) & {$[13]$} & $100 \%$ \\
Color fastness with artificial light & ISO 105-B02/94 & 4 \\
Color fastness to perspiration & ISO 105-E04/94 & 4 \\
Color fastness to washing & ISO 105-C01/89 & 4 \\
Color fastness to rubbing & ISO 105X12/01 & 4 \\
\hline
\end{tabular}

The practical effects of apparel comfort, with particular reference to the specific thermal properties of the fibers and yarns, play a rather secondary role in comparison with those of the air incorporated into the fabric structure and the absorption heat associated with the variation of the moisture content. In addition, they are indirectly dependent on the type of fiber as it may be more or less suitable for developing certain voluminous yarn and fabric characteristics. Therefore, the best way to evaluate the new product's performance is to measure it directly on the fabric instead of characterizing its yarns and/or fibers. Accordingly, the following tests were carried out to prove the effectiveness of the T4Innovation prototypes.

\subsection{Lightness}

The prototypes are characterized by an average weight of $350 \mathrm{~g} / \mathrm{m}^{2}$. Furthermore, yarns composing the innovative fabrics have respectively, 690 denier (volumized wool) and 600 denier (volumized nylon). Therefore, having a yarn with a high number of deniers with a weight that is compliant with the one stated by the requirements is a result that is considered excellent in terms of overall fabric lightness.

\subsection{Water-Vapor Resistance}

Designed fabrics are tested using a water-vapor resistance test, performed at a Temperature equal to $20{ }^{\circ} \mathrm{C} \pm 0.1{ }^{\circ} \mathrm{C}$ and controlled relative humidity ( $\mathrm{RH}$ ) equal to $65 \% \pm 3 \%$. Samples are pre-treated according to ISO 11092 standard. The obtained results show that all the fabrics conform to the desired values with an average performance of $6.05 \operatorname{Ret}\left[\mathrm{m}^{2} \mathrm{~Pa} / \mathrm{W}\right]$. Table 5 shows as an example the test performed on the sample 286,290 .

Table 5. Measurement of thermal and water-vapor resistance under steady-state conditions.

\begin{tabular}{ccc}
\hline Measurement & Unit of Measurement & Measured Value \\
\hline $\begin{array}{c}\text { Water vapor resistance (Ret)-mean } \\
\text { value for three samples }\end{array}$ & $\mathrm{m}^{2} \mathrm{~Pa} / \mathrm{W}$ & 6.31 \\
\hline
\end{tabular}

\subsection{Waterproofing}

To test fabrics waterproofing, the samples were conditioned in the atmosphere at $20 \pm 2{ }^{\circ} \mathrm{C}$ and $65 \pm 4 \% \mathrm{RH}$ in compliance with UNI EN ISO 139 and the evaluation was carried out as per Annex A of ISO 4920. The average value obtained for the products tested was ISO 4 corresponding to a high water repellency and in any case higher than the expected value. Figure 8 shows as an example the test performed on the sample with code 286,290. 


\begin{tabular}{|c|c|c|}
\hline \multicolumn{3}{|c|}{$\begin{array}{l}2037011 \text { Determination of resistance to surface } \\
\text { wetting (spray test) }\end{array}$} \\
\hline Pretreatment & & NONE \\
\hline Water temperature & ${ }^{\circ} \mathrm{C}$ & 20 \\
\hline Wetting index (specimen 1) & & 5 \\
\hline Wetting index (specimen 2) & & $4-5$ \\
\hline Wetting index (specimen 3 ) & & $4-5$ \\
\hline \multicolumn{3}{|c|}{$\begin{array}{l}2037011 \text { Determination of resistance to surface } \\
\text { wetting (spray test) }\end{array}$} \\
\hline Pretreatment & & $\begin{array}{l}\text { TEST PERFORMED AFTER } 1 \text { CYCLE (NORMAL) IN COMPLIANCE } \\
\text { WITH ISO } 3175-2\end{array}$ \\
\hline Water temperature & ${ }^{\circ} \mathrm{C}$ & 20 \\
\hline Wetting index (specimen 1) & & 5 \\
\hline Wetting index (specimen 2) & & $4-5$ \\
\hline Wetting index (specimen 3) & & 4-5 \\
\hline
\end{tabular}

Figure 8. Waterproofing test on sample from fabric with code 286,290.

Besides waterproofing, the fabrics were tested also in terms of water permeability. According to the Italian Standard UNI EN 20811:1993, water permeability is the resistance of the fabric to water penetration. In detail, constant hydrostatic pressure is applied for a long period (i.e., $24 \mathrm{~h}$ ) using a column of water at a temperature of about $20^{\circ}$. The result is conveyed by showing whether, with continuous passage or leakage, liquid penetration has occurred. The samples were acclimatized for $24 \mathrm{~h}$ in the atmosphere at $20 \pm 2{ }^{\circ} \mathrm{C}$ and $65 \pm 4 \% \mathrm{RH}$. The pressure is applied under the sample with a test area of $100 \mathrm{~cm}^{2}$ and increasing the water pressure with a delta of $10 \mathrm{~mm} / \mathrm{s}$ at a temperature of $20^{\circ} \mathrm{C}$. The average value obtained for the products tested was averagely about $2000 \mathrm{~mm}$ of $\mathrm{H}_{2} \mathrm{O}$ corresponding to a good level of waterproofing.

\subsection{UV Protection}

When ultraviolet radiation strikes textile materials, different types of interactions occur depending on the substrate and its conditions. In other words, the UV protection of textile and clothing materials is a function of the chemical and physical-chemical characteristics of the fibers, the reinforcement of the fabric, the thickness, the porosity, the extension of the fabric, the moisture content of the fabrics, the color and the finish of the fabric itself. Consequently, deriving a reliable UV protection rate for fabric is not trivial, and traditional testing has not yet been established. Hence, the experiment was carried out according to recent literary works aimed at understanding the limits of the acceptability of the person to UV rays, especially in relation to skin color. As demonstrated in [20] the levels of acceptability (critical dose) range from a minimum of $15 \mathrm{~mJ} / \mathrm{cm}^{2}$ to a maximum of $100-200 \mathrm{~mJ} / \mathrm{cm}^{2}$ (see Table 6).

Table 6. Critical UV dose depending to skin type.

\begin{tabular}{|c|c|c|c|}
\hline Skin Type & Critical Dose $\left[\mathrm{mJ} / \mathrm{cm}^{2}\right]$ & Self-Protection Time [min] & Risk Level \\
\hline White & $15-35$ & $5-12$ & $\begin{array}{l}\text { High risk of premature skin } \\
\text { aging, greatest risk of } \\
\text { developing skin cancer, burn } \\
\text { (and rarely tan) }\end{array}$ \\
\hline Brownish & $30-50$ & $10-15$ & Tan and occasionally burn \\
\hline Brown & $45-100$ & $15-35$ & $\begin{array}{l}\text { Sufficient level of melanin: } \\
\text { easily tan and rarely burn. }\end{array}$ \\
\hline Dark brown -Black & $100-200$ & $35-70$ & $\begin{array}{l}\text { Sufficient level of melanin: } \\
\text { easily tan and very } \\
\text { rarely burn. }\end{array}$ \\
\hline
\end{tabular}

Since the T4Innovation prototype is designed for men's and women's clothing in the adult age of any nationality, the minimum value that is required must be lower than the minimum critical value shown in Table 6 (i.e., $10 \mathrm{~mJ} / \mathrm{cm}^{2}$ ). A spectroradiometer is used to measure the real dose of UV radiation that passes through the newly designed fabrics. The part of the radiation that is transmitted through the fabric and reaches the skin is called the "transmission component". The protection to this 
component, UPF, increases with the density of the fabric and is inversely proportional to the porosity (i.e., UPF $=100$ /porosity). In detail, the UPF rate indicates how much of the sun's UV radiation is absorbed by the fabric. For example, a fabric with a UPF rating of 50 only allows $1 / 50$ th of the sun's UV radiation to pass through it. To achieve a minimum UPF score of 15 , which roughly corresponds to a transmission of $10 \mathrm{~mJ} / \mathrm{cm}^{2}$ at the daily average hourly irradiance standard value of $700 \mathrm{~W} / \mathrm{m}^{2}$, the fabric coverage factor must be greater than $93 \%$ and the fabric thickness greater than $1.5 \mathrm{~mm}$.

With regard to the type of fiber, from literature data [21] it can be deduced that the wool-synthetic fiber mix has average UPF values around 20-24 (if mixed in percentage 50\%) while natural fibers such as linen or cotton allow higher values (e.g., UPF $=50$ ). As far as color is concerned, as can be widely expected, the highest values of UPF are obtained for the white color.

For the T4Innovation prototypes developed in the paper, the coverage factor is $96.2 \%$, thus guaranteeing a UPS value of at least 23-24. The thickness of the fabric, equal to $2.5 \mathrm{~mm}$, offers additional protection from the fabric, which, therefore, in theory, has an overall value of UPF of at least 25-28. It is important to note that for Type 1 and Type 2 the percentage of wool fibers is, respectively, $60 \%$ and $67 \%$. Since these fibers have a broad spectrum absorption range of $280-400 \mathrm{~nm}$ the main discriminating factor for the measuring of UV protection is related to the color used in dyeing (for the prototypes developed, goes from beige to red). The calculated UPS values for the prototypes are in Table 7.

Table 7. Estimated UPF value for T4Innovation prototypes.

\begin{tabular}{cc}
\hline T4Innovation Prototype & UPF Value $\mathbf{( \pm \mathbf { 1 0 } \% )}$ \\
\hline 284,291 & 30 \\
284,292 & 29 \\
284,293 & 28 \\
286,269 & 30 \\
285,980 & 25 \\
285,989 & 25 \\
286,290 & 28 \\
\hline
\end{tabular}

Therefore, although it is a fabric intended for making winter clothes (and therefore not specifically designed for sun protection), the T4Innovation fabric still offers a quality ranging from good to very good protection, even in the darkest (red) color and in any case in line with what was estimated as a requirement in Section 1. As already mentioned, the measured UPF value is not standardized to date. Consequently, the measurement has a confidence value equal to $10 \%$.

\subsection{Clothing Insulation}

Thermal resistance $R$ is the ratio between the absolute temperature difference $\Delta T$ between the two faces of the insulating material (i.e., the fabric) and the amount of thermal energy transferred in the unit of time (thermal flow $\phi$ ) through the unit of surface $d$. This parameter is certainly one of the most interesting for the T4Innovation fabric.

Thermal resistance in fabrics can be measured in Clo $\left[0.155 \frac{\mathrm{m}^{2} K}{W}\right]$ where $1 \mathrm{Clo}$ is the amount of insulation that allows a person at rest to maintain thermal equilibrium in an environment at $21^{\circ} \mathrm{C}$ in a normally ventilated room $(0.1 \mathrm{~m} / \mathrm{s}$ air movement). Accordingly, the thermal resistance can be evaluated as follows:

$$
R=\left(\frac{d \Delta T}{\phi}\right)_{\text {fabric }}+\left(\frac{d \Delta T}{\phi}\right)_{\text {air }}+\left(\frac{d \Delta T}{\phi}\right)_{\text {other }_{\text {garments }}},
$$

where:

- $\quad\left(\frac{d \Delta T}{\phi}\right)_{\text {fabric }}$ represents the resistance to the opposite heat flow of T4Innovation; 
- $\quad\left(\frac{d \Delta T}{\phi}\right)_{\text {air }}$ represents the resistance to the opposite heat flow of the air layer between the clothes and the skin;

- $\left(\frac{d \Delta T}{\phi}\right)_{\text {other } \text { garments }_{\text {s }}}$ represents the resistance offered by other clothes underneath the fabric (e.g., underwear).

Considering to realize a coat with the innovative fabric and to have underlying clothing consisting of short-sleeved knitwear (underwear), a long-sleeved shirt and a light long-sleeved sweater, from data calculated in the literature (UNI EN ISO 9920:2004) it is possible to obtain the following values:

$$
\left\{\begin{array}{c}
\left(\frac{d \Delta T}{\phi}\right)_{\text {fabric }}=0.52 \\
\left(\frac{d \Delta T}{\phi}\right)_{\text {air }}=0.20 \\
\left(\frac{d \Delta T}{\phi}\right)_{\text {underwear }}=0.42
\end{array}\right.
$$

Therefore, an overall value of $R=1.6 \mathrm{Clo}$ is obtained. This is in line with what was foreseen in the requirements.

\subsection{Pilling Resistance}

Pilling is an undesired defect of textile fabrics, consisting of a surface characterized by a number of roughly spherical masses made of entangled fibers. The fabric's pills formation (i.e., the so-called "resistance to pilling") is typically measured using procedures described in Standards such as the D4970/D4970M-10e1 (ASTM, 2010) and the UNI EN ISO 12945-2004. Since fabrics take a long time to be pilled in normal use, resistance to pilling needs to be tested by simulated accelerated wear, followed by a visual assessment of the degree of pilling based on a visual comparison of the sample to a set of test images. T4Innovation prototypes were tested according to the ISO12947 standard, by using the Martindale tester [22] and samples are evaluated in a scale varying in the range $[1 \div 5]$ where 1 indicates "severe pilling" and 5 indicates "no pilling". In addition, intermediate values (e.g., 2, 3) can be measured. Table 8 shows the results of the pilling evaluation for the seven prototypes, assessed after 10,000 cycles. The average value for the whole set of fabrics is equal to 3,4 .

Table 8. Pilling evaluation assessed using Martindale test, after 10,000 cycles.

\begin{tabular}{cc}
\hline T4Innovation Prototype & Pilling Value \\
\hline 284,291 & 3,4 \\
284,292 & 3,4 \\
284,293 & 4 \\
286,269 & 4 \\
285,980 & 3,4 \\
285,989 & 3,4 \\
286,290 & 4 \\
\hline
\end{tabular}

\section{Discussion and Conclusions}

Two distinct types of businesses characterize the textile industry's current scenario. On one hand, in countries with low labor costs, there are companies operating and introducing policies aimed at low-cost mass production. Conversely, with particular reference to Europe and the United States, there are operators who invest considerable resources in technologies for product differentiation and to improve product quality. In these countries, and in particular, in Italy, the textile sector is, therefore, playing the card of innovation in technologies, processes, and materials, to move from traditional markets (where quality, cost and delivery times remain priorities) to new markets where performance, flexibility, functionality and consumer orientation become priorities. The main problem in this sector is the speed with which new technologies are acquired by both industry and consumers-the level of acceptance of new products and textiles varies greatly, even in the most advanced areas. 
Textile materials need to become the innovative substrate for a wide range of new applications, enabling the creation of technologically advanced products that guarantee protection, comfort, and high performance.

In this context, the present work introduced a new kind of product consisting of triple-layer thermo-insulated innovative fabrics in which the thermal insulation is obtained using appropriate volumized yarns. The overall performance of the newly devised fabrics is in Table 9.

Table 9. Overall performance of the newly devised fabrics.

\begin{tabular}{cc}
\hline Performance Parameter & Obtained Value \\
\hline Lightness & $350 \mathrm{~g} / \mathrm{m}^{2}$ \\
Breathability & $6.05 \mathrm{Ret}$ \\
Waterproofing & $\mathrm{ISO} 4$ \\
Ultra Violet protection & $25-28$ \\
Clothing insulation & $1.6 \mathrm{Clo}$ \\
Pilling resistance & 3,4 \\
\hline
\end{tabular}

Designed fabrics, therefore, demonstrated effective in ensuring thermal insulation in a reduced thickness; they are characterized by excellent aesthetic properties thus paving the way to the design of fashion and stylish winter products, which are cornerstones of the fashion textile industry. Future works will be addressed to include in the manufacturing process a progressive percentage of regenerated wool to create the volumized yarn. This would enhance furtherly the ecological sustainability [23] of T4Innovation fabrics, which could rapidly penetrate the international market.

\section{Patents}

Part of this work is now patent pending. Patent No. is F1.M0104.42.IT.1.

Author Contributions: Conceptualization, R.F. and Y.V.; methodology, R.F. and Y.V.; validation, F.M.; formal analysis, R.F. and Y.V.; investigation, R.F. and Y.V.; resources, F.M.; writing R.F. and Y.V.; supervision, F.M. All authors have read and agreed to the published version of the manuscript.

Funding: This research was funded by TUSCANY REGION under the POR FESR 2014-2020 Program.

Conflicts of Interest: The authors declare no conflict of interest.

\section{References}

1. Karkkainen, R.L.; Sankar, B.V.; Tzeng, J.T. Strength prediction of multi-layer plain weave textile composites using the direct micromechanics method. Compos. Part B Eng. 2007, 38, 924-932. [CrossRef]

2. Stanković, S.B.; Popović, D.; Poparić, G.B. Thermal properties of textile fabrics made of natural and regenerated cellulose fibers. Polym. Test. 2008, 27, 41-48. [CrossRef]

3. Zhang, J.; Zhang, X.; Fang, K.; Shu, D.; Gong, J.; Liu, X. Effect of the water content of padded cotton fabrics on reactive dye fixation in the pad-steam process. Coloration Technol. 2017, 133, 57-64. [CrossRef]

4. William, K.; Stump, W.L. Process for Making a Thermally Self-Bonded Low Density Nonwoven Product. U.S. Patent No. 3,589,956, 29 June 1971.

5. Brzeziński, S.; Malinowska, G.; Nowak, T. High-tech sports clothing with a high comfort of use made from multi-layer composite materials. Fibres Text. East. Eur. 2005, 13, 90-93.

6. Gnanauthayan, G.; Rengasamy, R.S.; Kothari, V. Heat insulation characteristics of multi-layer nonwovens. Res. J. Text. Appar. 2018, 22, 94-108.

7. Das, D.; Pourdeyhimi, B. Compressional and recovery behaviour of high loft nonwovens. Indian J. Fibre Text. Res. 2010, 35, 303-309.

8. Kaleeswaran, P.; Kothari, V.K. Thermal resistance of nonwoven waddings. J. Text. Inst. 2017, 108, $1657-1661$. [CrossRef]

9. Matusiak, M.; Kowalczyk, S. Thermal-insulation properties of multilayer textile packages. AUTEX Res. J. 2014, 14, 299-307. [CrossRef] 
10. Harding, W.A. Polarguard-A Unique Polyester Fiberfill. J. Ind. Text. 1979, 8, 226-229. [CrossRef]

11. Black, S.; Kapsali, V.; Bougourd, J.; Geesin, F. Fashion and function-Factors affecting the design and use of protective clothing. In Textiles for Protection; Woodhead Publishing: Cambridge, England, 2005; pp. 60-89.

12. Barella, A. A Direct Method for Measuring Yarn Diameters and Bulk Densities under Conditions of Thread Flattening. J. Text. Inst. Trans. 1960, 51, T293. [CrossRef]

13. Elmogahzy, Y. Structure and mechanics of yarns. In Structure and Mechanics of Textile Fibre Assemblies; Woodhead Publishing: Cambridge, England, 2019; pp. 1-25.

14. ISO 11092. Textiles. Determination of Physiological Properties. Measurement of Thermal and Water-vapour Resistance under Steady-state Conditions. Available online: https://www.iso.org/standard/65962.html (accessed on 2 January 2020).

15. Verdu, P.; Rego, J.M.; Nieto, J.; Blanes, M. Comfort Analysis of Woven Cotton/Polyester Fabrics Modified with a New Elastic Fiber, Part 1 Preliminary Analysis of Comfort and Mechanical Properties. Text. Res. J. 2009, 79, 14-23. [CrossRef]

16. Furferi, R.; Governi, L. The recycling of wool clothes: An artificial neural network colour classification tool. Int. J. Adv. Man. Tech. J. 2008, 37, 722-731. [CrossRef]

17. Furferi, R.; Carfagni, M. Colour mixing modelling and simulation: Optimization of colour recipe for carded fibres. Model. Simul. Eng. 2010, 6, 487678. [CrossRef]

18. Holeczek, K.; Starke, E.; Winkler, A.; Dannemann, M.; Modler, N. Numerical and Experimental Characterization of Fiber-Reinforced Thermoplastic Composite Structures with Embedded Piezoelectric Sensor-Actuator Arrays for Ultrasonic Applications. Appl. Sci. 2016, 6, 55. [CrossRef]

19. Azeem, M.; Ahmad, Z.; Wiener, J.; Fraz, A.; Siddique, H.F.; Havalka, A. Influence of weave design and yarn types on mechanical and surface properties of woven fabric. Fibres Text. East. Eur. 2018.

20. Saravanan, D. UV protection textile materials. AUTEX Res. J. 2007, 7, 53-62.

21. Momen, S.; Sarkany, R. Photoprotection in the Prevention of Photodamage and Cutaneous Cancer. Cutan. Photoaging 2019, 19, 275.

22. Furferi, R.; Governi, L.; Volpe, Y. Machine vision-based pilling assessment: A review. J. Eng. Fibers Fabr. 2015, 10, 79-93. [CrossRef]

23. Castro, A.M.; Nogueira, V.; Lopes, I.; Rocha-Santos, T.; Pereira, R. Evaluation of the Potential Toxicity of Effluents from the Textile Industry before and after Treatment. Appl. Sci. 2019, 9, 3804. [CrossRef] 